\title{
Wind Turbine Control Using PI Pitch Angle Controller
}

\author{
Abdulhamed Hwas and Reza Katebi \\ Industrial Control Centre, University of Strathclyde, Glasgow, UK \\ Email: Abdulhamed.hwas@eee.strath.ac.uk,r.katebi@eee.strath.ac.uk
}

\begin{abstract}
This paper suggests two methods to calculate the gains of a proportional-Integral pitch angle controller for a $5 \mathrm{MW}$ wind turbine. The first method is analytical and the second one is based on simulation. Firstly, the power coefficient characteristics for different pitch angles are calculated. Secondly, the output powers vs. rotor speed curves from cut-in to cut-out wind speeds are simulated. The results from first and second analyses used to find the control gains at different wind speeds. Finally, the results are compared using a wind turbine model to determinate turbine's tracking characteristic.
\end{abstract}

Keywords: Wind turbine, PI controller, Pitch angle, Quadratic control law, Tracking

\section{INTRODUCTION}

Pitch variable-speed wind turbines have become the dominating type in recent years. There are typically two control strategies for the variable-speed wind turbines. In low wind speed below a rated value, the speed controller can continually adjust the speed of the rotor to maintain the speed at a level, which gives the maximum power coefficient, and then the efficiency of the turbine will be increased. Pitch angle regulation is required in conditions above the rated wind speed when the rotational speed is kept constant. Small changes in pitch angle can affect the power output. The purpose of the control can be summarised in three aims as following:

1. Optimising the power output when a wind speed is less than rated wind speed.

2. Keeping the rotor power at design limits when the wind speed is above rated wind speed.

3. Minimize the fatigue loads of the turbine mechanical components.

The design of the controller must take into account the effect on loads, and the controller should ensure that extreme loads would not result from any control action. It is possible to go further, and clearly design the controller with the reduction of certain fatigue loads as an additional objective.

In an active Proportional-Integral-Derivative (PID) pitch controller, the sensitivity of aerodynamic power to the rotorcollective blade-pitch angle is negative. With positive control gains, the derivative term will then increase the effective inertia of the drive train. Hansen et al. (2005) recommend using PI controller. However, Boukhezzar et al. (2007) suggest using only a proportional pitch controller based on the test results that show a more complex controller (PI and PID) will make the pitch control more turbulent without a significant improvement of the power regulation performance. Moreover, it is shown that using an advanced control strategy such as LQG control design technique ensures a better power tracking than the PID, but this turns out to be still insufficient to meet all the control objectives (Eisenhut et al., 2007). This paper has focused on the design of PI pitch angle control for a $5 \mathrm{MW}$ wind turbine.

The paper is organised as follows. The pitch control design is discussed in section 2. The models for control design are presented in section 3 . The actuator model is discussed in section 4 . The controller gains are calculated in section 5 . The conclusion is given in section 6 .

\section{PITICH CONTROL}

Adjusting the pitch angle of the blades, as shown in Fig.1, provides an effective means of limiting turbine performance in strong wind speeds. To put the blades into the desired position, electric or hydraulic pitch servos are employed.

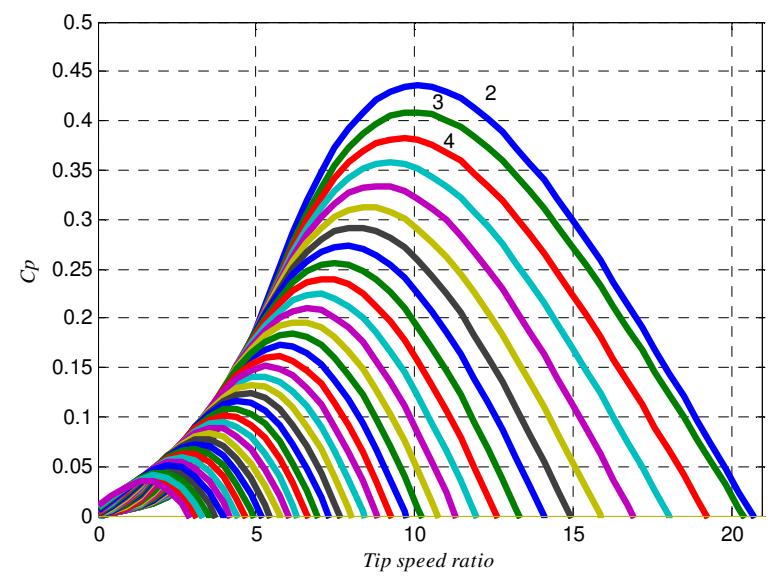

Fig. 1. Power coefficient characteristics for different pitch angles ( pitch $\left.=2^{\circ}, 3^{\circ}, 4^{\circ}, \ldots, 39^{\circ}\right)$.

The blade control strategies can be classified according to the input signals used to generate the pitch set point (Zhang et al., 2008): 
- Ideally, the pitch angle reference can be obtained from the curve of the pitch angle versus wind speed. This control strategy is not an acceptable method, as the effective wind speed cannot be measured accurately.

- The error signal of the generated power is sent to a controller to produce a reference pitch angle.

- The error between the generator rotor speed and its set point is sent to the controller to produce a reference value for the pitch angle. This method is most popular, since it is more accurate.

\section{SOME USEFUL MODELS FOR CONTROL}

The power in the wind is proportional to the cube of the wind speed and can be expressed as:

$$
P=0.5 \rho \mathrm{Av}^{3}
$$

where $\rho$ is air density, $A$ is the area swept by blades and $\mathrm{v}$ is wind speed.

A wind turbine can only extract part of the power from the wind, which is limited by the Betz limit (maximum 59\%). This fraction is described by the power coefficient of the turbine, which is a function of the blade pitch angle and the tip speed ratio. Therefore, the mechanical power of the wind turbine extracted from the wind is:

$$
P_{w t}=0.5 \rho A v 3 \mathrm{C}_{\mathrm{p}}(\beta, \lambda)
$$

where $C_{p}$ is the power coefficient of the wind turbine, $\beta$ is the blade pitch angle and $\lambda$ is the tip speed ratio. The value of $C_{p}$ is highly non-linear and varies with the wind speed, the rotational speed of the turbine, and the turbine blade parameters such as a pitch angle. In this paper value of the $\mathrm{C}_{\mathrm{p}}(\beta, \lambda)$ is calculated as:

$C_{p}=0.5176\left(\frac{116}{\lambda_{i}}-0.4 \beta-5\right) e^{\frac{-21}{\lambda_{i}}}+.0068 \lambda$

where:

$\frac{1}{\lambda_{i}}=\frac{1}{\lambda+0.08 \beta}-\frac{0.035}{\beta^{3}+1}$

The tip speed ratio is defined as the ratio between the blade tip speed and the wind speed.

$$
\lambda=\frac{\omega_{w t} R}{v}
$$

where $\omega_{w t}$ the turbine rotor speed, and $\mathrm{R}$ is is the radius of the wind turbine blade.

Thus any change in the rotor speed or the wind speed induces a change in the tip speed ratio leading to power coefficient variation. Fig. 2 shows the mechanical power for $5 \mathrm{MW}$ wind rotor vs. rotor speed at different wind velocity.

The power extracted by the turbine increases as the wind speed increases. At rated wind speed, the generating power reaches the rated power of the turbine. If the wind speed continues to rise the output power will also increase, so the control system is required to keep the power constant at the design limit. The turbine is shut down at speed exceeding cutout wind speed for the safety consideration.
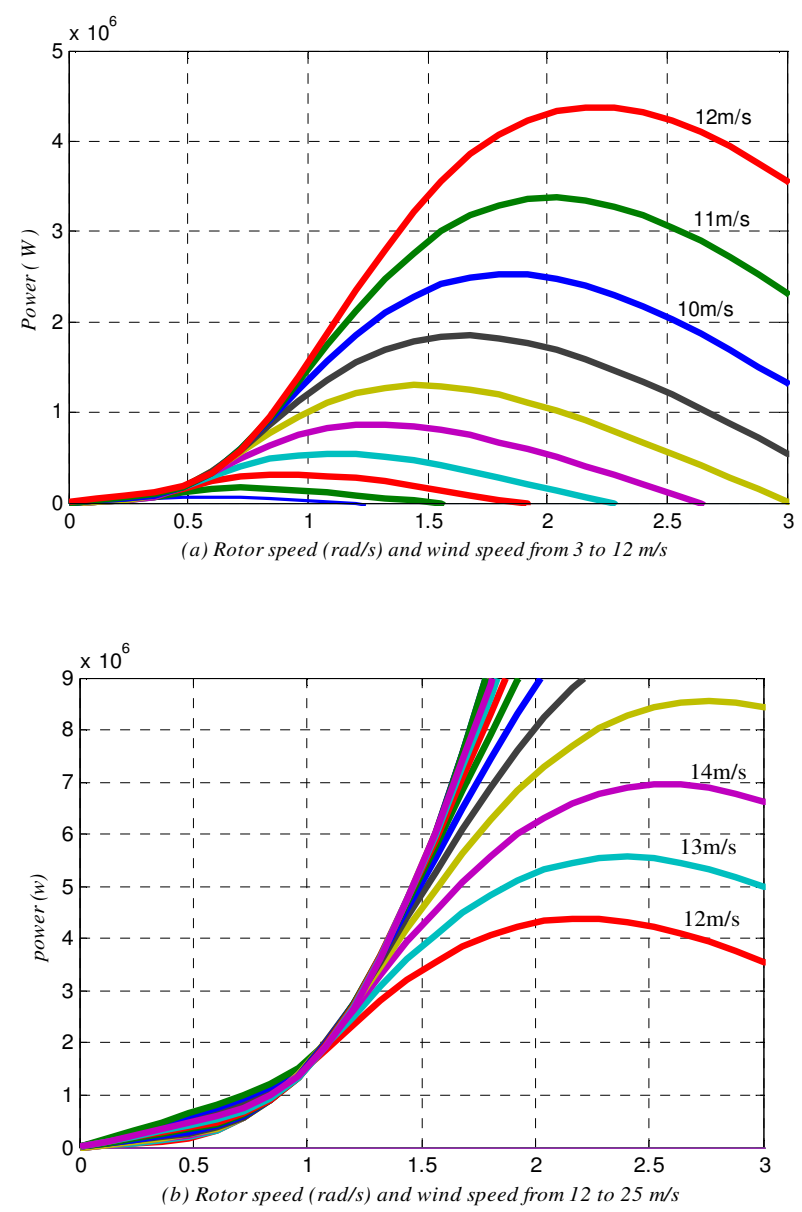

Fig. 2. Wind turbine output Power vs. Rotor speed for different wind speeds $(3,5,6, \ldots, 25 \mathrm{~m} / \mathrm{s})$

\section{ACTUATOR MODEL}

The pitch actuator consists of a mechanical and a hydraulic system, which is used to turn the blades along their longitudinal axis. The actuator model describes the dynamic behaviour between a pitch demand $\beta_{d}$ from the pitch controller and the measurement of a pitch angle $\beta$.

The dynamics of the blades are non-linear with saturation limits on both pitch angle and pitch rate. This saturation is caused by high frequency components of the pitch demand spectrum, via measurement noise, and spectral peaks induced by rotational sampling (Feng et al., 2008). In this paper, the constraint is not considered. The actuator dynamic is modelled as in (Eisenhut et al., 2007). The change in the pitch angle is: 
$\dot{\beta}=\frac{\beta_{d}-\beta}{\tau_{\beta}}$

From above equation, the transfer function for the actuator is:

$\frac{\beta}{\beta_{d}}=\frac{1}{\tau_{\beta} s+1}$

where $\tau_{\beta}$ is a time constant depends on the pitch actuator.

\section{DETERMINATION OF THE QUADRATIC AND PI CONTROLLER GAINS}

Variable speed variable pitch wind turbine modes of operation take into account rotational speed and power limitations. These modes are:

1. Operation at minimal value (near to cut off in wind speed) the tip speed ratio is optimised by pitch control.

2. Variable speed fixed pitch operation; the operating point describes the optimal regime's characteristic. Here, a torque control scheme is used to optimize the power.

3. Fixed speed variable pitch operation, the rotational speed limitation at its rated value. In this mode, pitch angle controller achieves power limitation.

\subsection{Selection of the operating point}

Nominal parameters of a 5MW WT as shown in Table 1 are used (Wang et al., 2008). It is assumed that the wind speed is $15 \mathrm{~m} / \mathrm{s}$. From Fig. 2 this wind speed is above the rated speed, so in this case the operating point is in mode 3 . Then rotational speed must be equal to rated rotor speed $\left(\omega_{w t_{-} r e f}\right)$. Thus, the desired constant speed of the turbine is $1.87 \mathrm{rad} / \mathrm{s}$. $\lambda$ and $\mathrm{Cp}$ operating points were selected by using Figs 3 and 4. The pitch angle is $9.65^{\circ}$ as selected from the power coefficient curve of Fig. 1. By repeating the same steps for each wind speed the optimal values of $\lambda, \mathrm{Cp}$ and pitch angle for mode 3 can be calculated as shown in the Table 2 .

\subsection{Quadratic control law}

Below rated wind speed, optimizing the power output of the wind turbine is achieved by using the torque control scheme for a variable-speed wind turbine, which is written as (Johnson et al., 2006):

$\mathrm{Te}(\mathrm{ref})=\frac{\mathrm{P}_{\mathrm{wt}(\max )}}{\omega_{m}}$

where $T_{e}$ (ref) is the reference electrical torque, $C_{p_{-} \text {max }}$ is the maximum power coefficient and $\lambda_{\text {opt }}$ is the tip speed ratio at $\mathrm{C}_{\mathrm{p}_{-} \max }$. From equation (2) we can estimate $\mathrm{T}_{\mathrm{e}_{-}(\mathrm{ref})}$ which maximizes output power as:
$T_{e(r e f)}=\frac{0.5 \rho \pi R^{2} C_{p_{-} \max }\left(\frac{R \omega_{w t}}{\lambda_{\text {opt }}}\right)^{3}}{\omega_{m}}$

Since in the steady state $\omega_{m}=n g \omega_{w t}$, we defined the optimal gain:

$K_{\text {opt }}=\frac{0.5 \rho \pi R_{w}^{5} C_{p_{-} \max }}{\lambda_{\text {opt }}^{3} n_{g}^{3}}$

Thus, the quadratic control law can be rewritten as:

$T_{e(r e f)}=K_{o p t} \omega_{m}^{2}$

Note that the transmission friction losses are not considered (Pena et al., 1996). From Equation (10) it is clear that the optimal gain varies from turbine to turbine, even if they have the same rated power. Furthermore, these can also be changed during a turbine life's period.

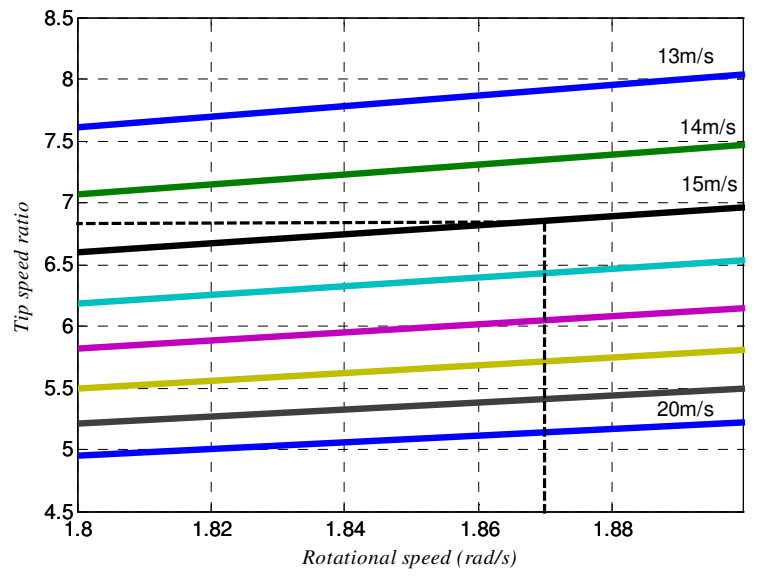

Fig. 3 Tip speed ratio vs. wind turbine rotational speed shows operating mode 3 , fixed rotational speed and variable pitch operation.

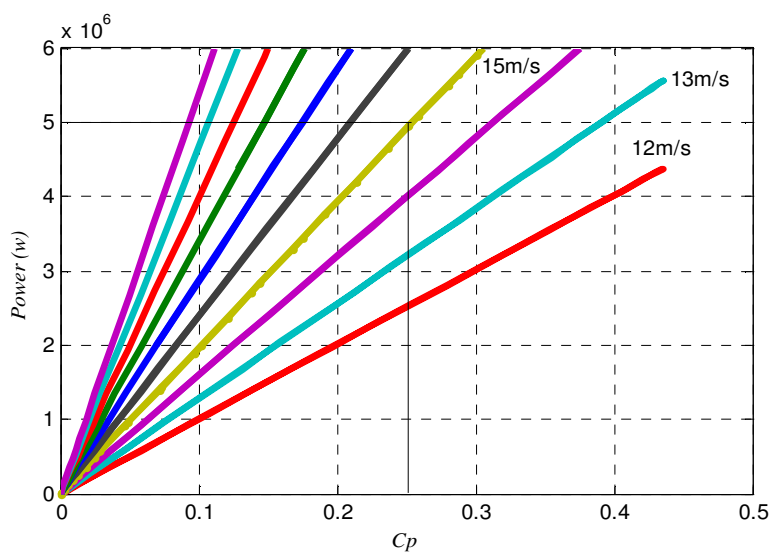

Fig. 4. Wind turbine power output vs. Cp shows operating mode 3 , fixed rotational speed and variable pitch operation. 


\subsection{Theoretical method to calculate PI controller gains}

The output signal from PI controller is $\beta_{d}$ as showing in the Fig. 5, which also contains the actuator's transfer function that obtained from equation (7). Then PI controller and desired pitch angle can be expressed as follows:

$\beta_{d}=K_{p} e+K_{i} \int e d t$

where

$$
e=\omega_{m_{-} r e f}-\omega_{m}
$$

To find the solution, let:

$$
x=K_{i} \int e d t
$$

or

$$
\frac{d x}{d t}=K_{i} e
$$

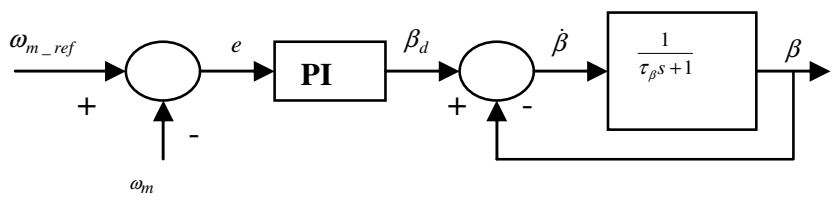

Fig. 5. PI Pitch controller

From equations (12) and (14), the partial derivatives of $\beta_{d}$, with respect to $e$, is expressed as follows:

$\frac{d \beta_{d}}{d e}=K p+\frac{d x}{d e}=K p+\frac{d x / d t}{d e / d t}=K p+K_{i} \frac{e}{\frac{d e}{d t}}$

For an adjustable-slip asynchronous generator, the variation range of $e$ is very small. Moreover, $\mathrm{K}_{\mathrm{p}}$ is far greater than $\mathrm{K}_{\mathrm{i}}$. Hence equation (16) can be simplified as follows.

$K_{p}=\frac{d \beta_{d}}{d e}$

$d \beta_{d}=\beta_{d}\left(\beta_{d 0}=0\right.$ (initial value $\left.)\right)$, to find the direct relation between $\beta$ and $\beta_{d}$, we reduce inner closed loop for the actuator in Fig. 5, to the forward path, and assuming $\tau_{\beta}=1 \mathrm{~s}$. Thus, we obtain the following transfer function:

$\frac{\beta}{\beta_{d}}=\frac{1}{s+2}$

In the steady state $\mathrm{s} \Rightarrow 0$, and $\beta_{\boldsymbol{d}}=2 \beta$. From the equations (13, 16, and 17), the $\mathrm{Kp}$ and $\mathrm{K}_{\mathrm{i}}$ are:

$$
K_{p}=\frac{2 \beta}{\omega_{m_{-} r e f}-\omega_{m}}
$$

$\boldsymbol{K}_{i}=\frac{1}{\omega_{m_{-} r e f}-\omega_{m}} *\left(\frac{2 \beta}{\omega_{m_{-} r e f}-\omega_{m}}-\boldsymbol{K} \boldsymbol{p}\right) * \frac{\partial \Delta \omega}{\partial t}$

From equations $(19,20)$ the value of the integral coefficient $\mathrm{K}_{\mathrm{i}}=0$, since middle part of the equation (20) equal zero.

Table 1. Parameters of the 5MW WT and controller

\begin{tabular}{|l|c|c|}
\hline \multicolumn{1}{|c|}{ Description } & Parameter & Value \\
\hline Rated turbine power & $\mathrm{P}_{\mathrm{n}}$ & $5 \mathrm{MW}$ \\
\hline Turbine blade length & $\mathrm{R}$ & $55 \mathrm{~m}$ \\
\hline Gearbox ratio & $\mathrm{n}_{\mathrm{g}}$ & 60.88 \\
\hline Air density & $\rho$ & $1.225 \mathrm{~kg} / \mathrm{m}^{3}$ \\
\hline $\begin{array}{l}\text { Reference generator } \\
\text { speed }\end{array}$ & $\omega_{m_{-} r e f}$ & $113.85(\mathrm{rad} / \mathrm{s})$ \\
\hline Cut in wind speed & $\mathrm{V}_{\text {cin }}$ & $3 \mathrm{~m} / \mathrm{s}$ \\
\hline Cut out wind speed & $\mathrm{V}_{\text {cout }}$ & $25 \mathrm{~m} / \mathrm{s}$ \\
\hline
\end{tabular}

\subsection{Simulation based method to calculate PI gains}

Above rated wind speed, the rotor power must be kept at below design limits by using the PI pitch angle controller. Figs. (5) and (6) demonstrate the Pitch angle PI controller principle.

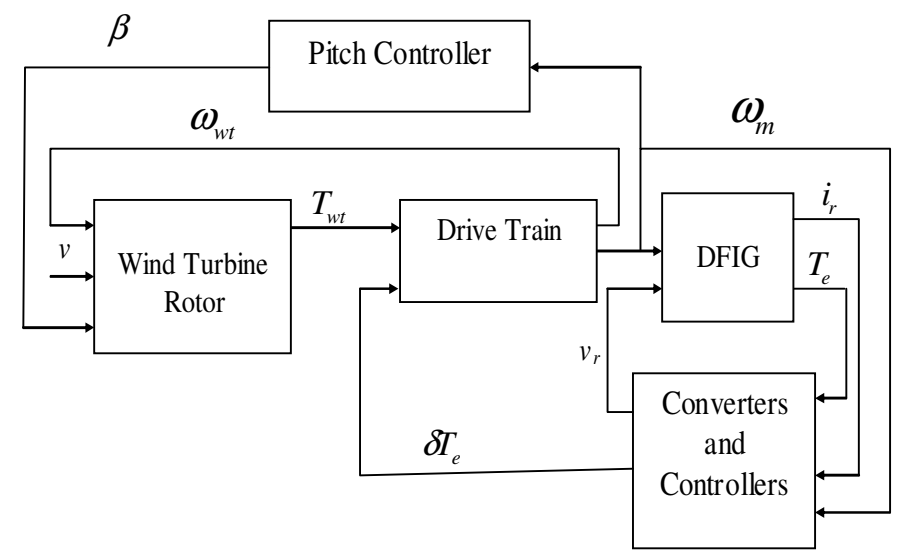

Fig. 6. Block diagram for the control of the mechanical part of 5MW wind turbine in a strong wind. $v_{r}$ and $i_{r}$ are voltage and current of the DFIG rotor respectively.

Fig. 6 shows the block diagram of the mathematical models for the main components of 5MW wind turbine system, particularly aerodynamic, two-mass drive train and generator. The torque controller is designed and investigated in previous work (Hwas, 2010). Wind turbine is nonlinear. Therefore, we need to determine PI gains in the following steps.

From Fig. 5 the relation between error and pitch angle $\beta$ is: 


$$
\frac{\beta(s)}{E(s)}=\left(K_{p}+\frac{K_{i}}{s}\right) \frac{1}{s+2}
$$

Since the values of $\beta$ and $\mathrm{E}$ are selected from Table 2 and the wind turbine model respectively, thus $\mathrm{K}_{\mathrm{P}}$ and $\mathrm{K}_{\mathrm{i}}$ can be calculated by using simulation to shape the responses in (21).

Fig. 7 shows the block diagram, which is implemented to calculate $\mathrm{K}_{\mathrm{P}}$ and $\mathrm{K}_{\mathrm{i}}$ by inserting data of wind turbine as input and gains as output. The simulation is implemented by MATLAB /Simulink software. The generator speed $\omega_{m}$ is fed back, and the rated generator speed reference is set to a value, $\omega_{m_{-} r e f}$. The error is input to the controller, which commands a change in the blade pitch angle. The new pitch angle requested is $\beta=\beta_{d}-\beta$. The actuator operates on a pitch rate command. The pitch rate is determined from the difference between the desired pitch angle and the measured blade pitch angle. By using this method, PI gains are obtained; those achieve desired rotor speed and output power is shown in Fig. 11. It is used to find control gains at different wind speeds $(13,14, \ldots 25 \mathrm{~m} / \mathrm{s})$, as presented in the Table 2 . The value of $K_{i}$ is very small $\left(K_{i}<<1 / 10000\right)$.

For example, fig. 8 shows the values of $\mathrm{K}_{\mathrm{P}}$ and $\mathrm{K}_{\mathrm{i}}$ at wind speed $15 \mathrm{~m} / \mathrm{s}$. Fig. 10 shows the response of the output pitch angle at different operating points (wind speed $=12,15,18$, $21 \mathrm{~m} / \mathrm{s}$ ). Here, we can notice at wind speed $12 \mathrm{~m} / \mathrm{s}$ is below the rated value; the controller should switch to the quadratic control law, $\mathrm{K}_{\mathrm{opt}}$.

To control the pitch angle and output power for non-linear wind turbine models a gain-scheduling scheme is implemented, which depended on the switch case block. The switch case block receives wind speed as a single input. It uses its input value to select a case condition that determines which subsystem to execute to give the value of the $K_{p}$ as output as shown in Fig. 9.

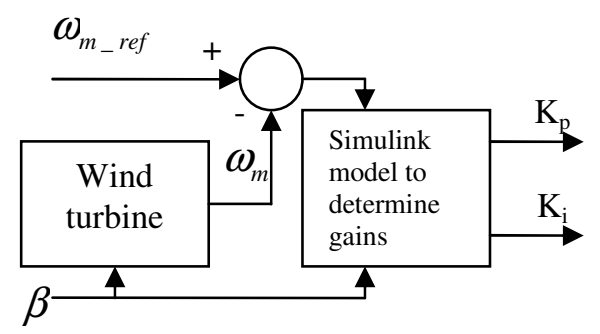

Fig. 7. Block diagram to calculate $\mathrm{K}_{\mathrm{p}}$ and $\mathrm{K}_{\mathrm{i}}$.

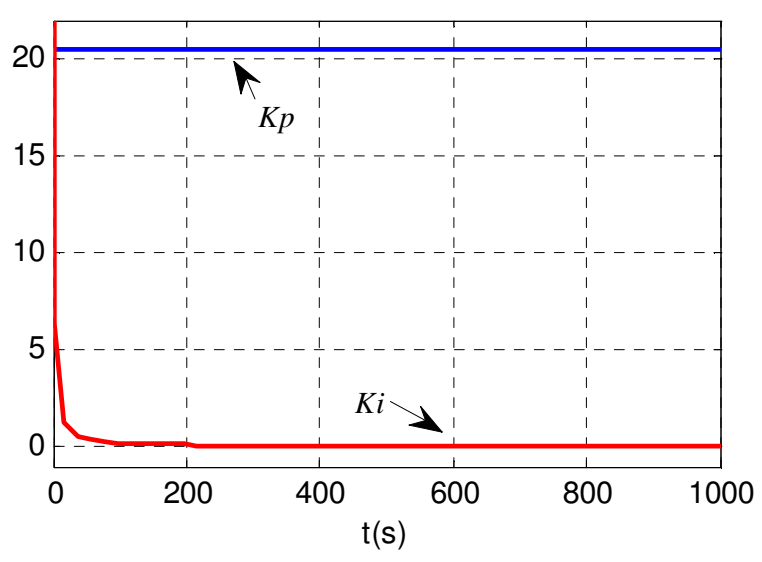

Fig. 8. Values of $K_{p}$ and $K_{i}$ at wind speed $15 \mathrm{~m} / \mathrm{s}$ those obtained using simulation-based method

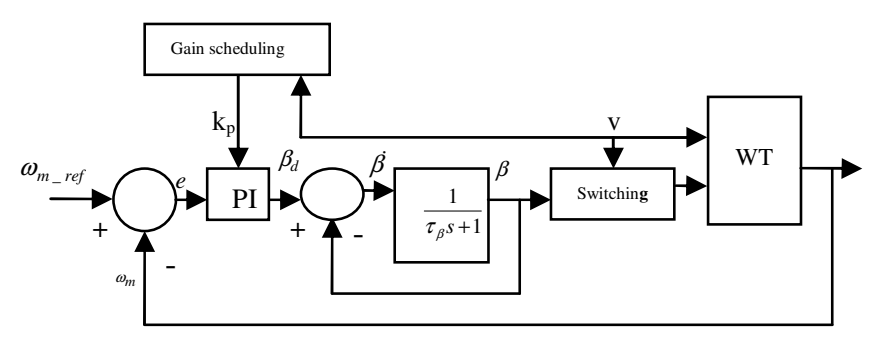

Fig. 9. Block diagram of the Pitch angle PI controller with gain scheduling and switching.

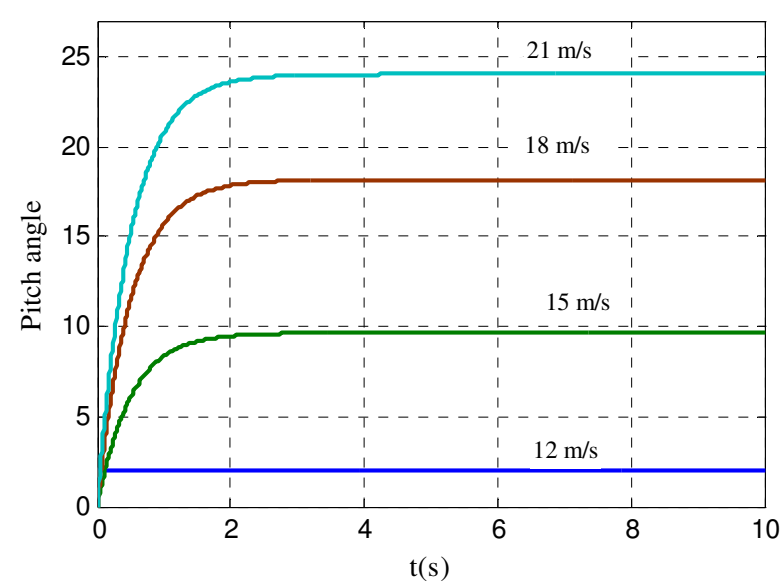

Fig. 10. Shows the simulation output of pitch angle at different operating points $($ wind speed $=12,15,18,21 \mathrm{~m} / \mathrm{s}$ )

The simulation output results for Turbine characteristics and tracking characteristic are represented in the fig. 11 proved the operating points of the wind turbine track the desired mode (wind turbine modes of operation take into account rotational speed and power limitations). 


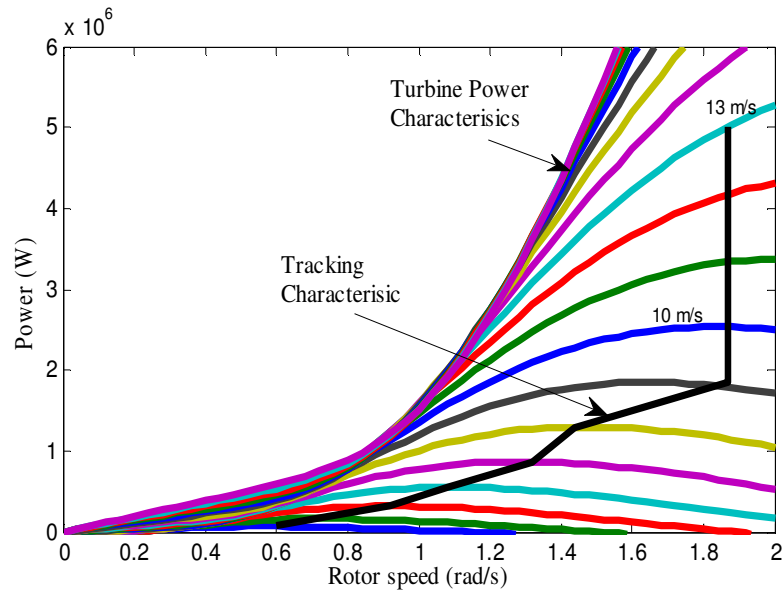

Fig. 11. Turbine characteristics and tracking characteristic, those are achieved by using the quadratic control law and PI controller

Table 2. Wind Turbine Characteristics

\begin{tabular}{|c|c|c|c|c|c|}
\hline \multicolumn{6}{|c|}{ Power Optimisation } \\
\hline $\begin{array}{c}\mathrm{V} \\
(\mathrm{m} / \mathrm{s})\end{array}$ & $\lambda$ & $\mathrm{Cp}$ & $\beta^{o}$ & $\mathrm{~K}_{\mathrm{opt}}$ & $\begin{array}{l}\omega_{w t_{-} r e f} \\
(\mathrm{rad} / \mathrm{s})\end{array}$ \\
\hline 3 & 11 & 0.43 & 2 & 1.3842 & 0.5984 \\
\hline 4 & 9.9 & 0.44 & 2 & 1.9242 & 0.7293 \\
\hline 5 & 10 & 0.43 & 2 & 1.796 & 0.9163 \\
\hline 6 & 9.9 & 0.44 & 2 & 1.9242 & 1.0846 \\
\hline 7 & 10 & 0.43 & 2 & 1.6726 & 1.3277 \\
\hline 8 & 9.9 & 0.44 & 2 & 1.9242 & 1.4399 \\
\hline 9 & 6.1 & 0.44 & 2 & 1.2513 & 1.87 \\
\hline 10 & 5.5 & 0.44 & 2 & 1.7161 & 1.87 \\
\hline 11 & 9.4 & 0.43 & 2 & 2.2568 & 1.87 \\
\hline 12 & 8.6 & 0.41 & 2 & 2.8219 & 1.87 \\
\hline \multicolumn{6}{|c|}{ Power limitation } \\
\hline $\begin{array}{c}\mathrm{V} \\
(\mathrm{m} / \mathrm{s})\end{array}$ & $\lambda$ & $\mathrm{cp}$ & $\beta^{o}$ & $\mathrm{~K}_{\mathrm{p}}$ & $\begin{array}{c}\omega_{w t_{-} r e f} \\
(\mathrm{rad} / \mathrm{s})\end{array}$ \\
\hline 13 & 7.9 & 0.39 & 2 & 24.09 & 1.87 \\
\hline 14 & 7.3 & 0.31 & 5.85 & 16.26 & 1.87 \\
\hline 15 & 6.8 & 0.25 & 9.65 & 20.51 & 1.87 \\
\hline 16 & 6.4 & 0.21 & 13 & 52.2 & 1.87 \\
\hline 17 & 6 & 0.17 & 15.75 & 33.48 & 1.87 \\
\hline 18 & 5.7 & 0.15 & 18.16 & 131.25 & 1.87 \\
\hline 19 & 5.4 & 0.13 & 20.23 & 146.57 & 1.87 \\
\hline 20 & 5.1 & 0.11 & 22.22 & 47.23 & 1.87 \\
\hline 21 & 4.8 & 0.09 & 24.03 & 21.8 & 1.87 \\
\hline 22 & 4.6 & 0.08 & 25.52 & 27.95 & 1.87 \\
\hline 23 & 4.4 & 0.07 & 26.9 & 29.46 & 1.87 \\
\hline 24 & 4.2 & 0.06 & 28.21 & 24.86 & 1.87 \\
\hline 25 & 4.1 & 0.06 & 29.15 & 150.38 & 1.87 \\
\hline
\end{tabular}

\section{CONCLUSIONS}

A PI based control design scheme was proposed for the control of blade pitch angle in variable speed wind turbine. One analytical method and one simulation based method was proposed to calculate the PI gains. Simulation results demonstrated good performance for both proposed PI schemes.

\section{REFERENCES}

Boukhezzara, B., Lupua, L.; Siguerdidjanea, H., and Hand, M. (2007). Multivariable control trategy for variable speed, variable pitch wind turbines. Renewable Energy, vol (32), 1273-1287.

Eisenhut, C., Krug, F., and Schram, C. (2007). WindTurbine Model for System Simulations Near CutIn Wind Speed. IEEE Transactions on Energy Conversion, vol (22), NO.2.

Feng, Gao., Daping, Xu., and Yuegang, L. (2008). Pitchcontrol for Large-scale Wind Turbine Based on Feed forward Fuzzy_PI. WCOICA, 25-27, Chongqing, China.

Hansen, H., and Larsen, L. (2005). Control design for a pitch-regulated, variable speed wind turbine. Riso, National Laboratory Roskilde, Denmark.

Hwas, A. (2010). Wind energy conversion system model report. Industrial Control Centre, University of Strathclyde, $U K$.

Johnson, K., Pao, L., Balas, M., and Fingersh, L. (2006). Control of variable-speed wind turbines: standard and adaptive techniques for maximizing energy capture. IEEE Control Systems Magazine, 26(3):70-81.

Pena, R., Clare, J., and Asher, G. (1996). Doubly-fed induction generator using back-tobackpwm converters and its application to variable-speed wind-energy generation. IEE Proc. Electr. Power Appl, 143(3):231-241.

Wang C. (2008).Control, stability analysis and grid integration of wind turbines". PhD Thesis, Imperial College London.

Zhang, J., Cheng, M., Chen, Z., and Fu, X. (2008). Pitch Angle Control for Variable Speed Wind Turbines. DRPT 2008. 6-9 April, China. 